\title{
DYNAMIC RESPONSE ANALYSIS METHOD FOR THE PEAK VALUE STAGE OF CONCRETE-FILLED STEEL TUBE BEAMS UNDER LATERAL IMPACT
}

\author{
Xiang-jie Kang ${ }^{1}$, Yan-hui Liu ${ }^{1, *}$, Lei Zhao ${ }^{2}$, Zhi-xiang Yu ${ }^{1,3}$, Shi-chun Zhao ${ }^{1,3}$ and Heng Tang ${ }^{1}$ \\ ${ }^{1}$ School of Civil Engineering, Southwest Jiaotong University, Chengdu, China \\ ${ }^{2}$ Department of Civil and Environmental Engineering, The Hong Kong Polytechnic University, Hong Kong, China \\ ${ }^{3}$ National Engineering Laboratory for prevention and control of geological disasters in land transportation, Chengdu, China \\ *(Corresponding author: E-mail: liuyanhui00@126.com)
}

\section{A B S T RA C T}

This paper proposes a dynamic response analysis method of concrete-filled steel tube (CFST) beams at the peak value stage under lateral impact load. Targeted calculation of the peak value stage, finite element analysis (FEA) was carried out to determine the calculation model suitable for the analysis of the peak value stage and the simplified trend curve of beam acceleration at the impact point. Then, an analysis method for calculating the dynamic response of a fixed-fixed supported CFST beam is proposed, which consists of the travelling hinge theorem and a prediction model of the simplified trend curve. The predicted simplified trend curve is applied to replace the motion constraint assumption of the impactor and beam in the travelling hinge model. In the meantime, the elastoplastic behaviour of the CFST beams is considered in the analysis process. Through the comparison of experimental results and analysis results, this analysis method can predict the time history curves of the acceleration and impact force of CFST beams reasonably.
A R T I C L E H IST TORY

$\begin{array}{ll}\text { Received: } & \text { 25 January } 2019 \\ \text { Revised: } & \text { 01 May } 2019 \\ \text { Accepted: } & \text { 19 May } 2019\end{array}$

\section{K E Y W O R D S}

Lateral impact;

Dynamic response;

Concrete filled steel tube;

Calculation method;

Peak value stage

\section{Introduction}

Due to the functional requirements of a structure, it is inevitable to analyse the dynamic response of structural members under ultimate loads. The lateral impact is one of the dynamic loads that cannot be ignored, which can cause serious damage and even the collapse of bridges and buildings [1,2]. Therefore, the impact resistance of structures has been studied by using several experiments and numerical simulations [3-9]. According to the impact load measured from lateral impact tests, the dynamic response process of a beam can usually be divided into three stages: the peak value stage, the platform stage, and the unloading stage [10]. The peak value stage appears earliest in the dynamic response process, which determines the initial state of the following stage. Moreover, the maximum value of the impact load also appears at the peak value stage. Consequently, it is of significance to gain insight into the peak value stage in the process of analysis and design.

The difficulty of calculation at the peak value stage consists in the estimation of the beam resistance. When the impact occurs rapidly, the resistance of the beam at the peak value stage may be completely provided by inertial force. The dynamic bending moment and the shear force in a structural member can only be balanced with the inertial resistance of the beam and the impact force of the impactor [11,12]. As a result, the beam supports have no significant influence on the impact process [13]. Correspondingly, the dynamic equilibrium equation is different from that of the static case due to their different boundary conditions. The method which can describe this inertial resistance process is the travelling hinge theorem [14], which has been used by Parkes $[15,16]$ to determine the dynamic responses of rigid plastic beams under lateral impact loads. In the calculation process, the travelling plastic hinge is used to replace the function of the supports. The impact force of the impactor can only be balanced with the inertial resistance of the beam before travelling hinge reaches the support constraint.

Nevertheless, the travelling hinge theorem has not yet been adopted to calculate the dynamic responses of structural members at the peak value stage, because this model assumes that the motion of both the impactor and beam are the same in the impact area. This motion constraint assumption is different from the actual phenomenon occurring at the peak value stage. However, Pham et al. $[17,18]$ show that the position of a plastic hinge could significantly affect the dynamic response of the structural beam because there is a possibility that the plastic hinge of one structural beam may not reach the support constraint during the dynamic response process. Therefore, when calculating the dynamic response of a structural member, it is necessary to describe the travelling process of the plastic hinge.

The concrete-filled steel tube (CFST) beam exhibits a high bearing capacity and good ductility; therefore, it has become the common form of structural members [19-22]. The CFST beam dynamic response process obtained from lateral impact tests [23-26] also includes the peak value stage, the platform stage, and the unloading stage. However, there are several methods for calculating the platform stages in CFST beams [27-30], whereas those for the peak value stage are rare. Only the analytical calculation performed by Wang et al. [31] includes the peak value stage. A transient force $(\mathrm{P})$-local indentation $(\delta)$ curve, which expresses a quality similar to contact stiffness, was introduced to describe the interaction between the impactor and beam. Although this method still does not obtain the accurate dynamic response of the beam at the peak value stage [31], it includes all three stages of the dynamic response process. The reason for the error occurring at the peak value stage may involve overlooking the motion of the plastic hinge. Overall, difficulties still exist in the calculation of the peak value stage of CFST beams.

This study is an attempt to address these difficulties in the calculation of the dynamic response of CFST beams at the peak value stage. Thus, finite element analysis (FEA) was conducted to investigate the dynamic behaviour of fixed-fixed supported CFST beams under lateral impact loads, and five lateral impact tests were adopted to verify the FEA results. Based on these results, an analysis calculation model suitable for the peak value stage as well as a simplified trend curve of the impact point acceleration was determined. Then, the dynamic responses of CFST beams at the peak value stage were calculated on the basis of the travelling hinge theorem and the prediction model of the simplified trend curve

\section{Dynamic response at the peak value stage}

\subsection{Test description}

Five lateral impact tests were carried out to obtain the dynamic response of CFST members under lateral impact at the peak value stage. The outer diameter $(D)$ of the CFST beams is $114 \mathrm{~mm}$, and the thicknesses of the steel tubes, which are made of mild steel, are $2.0 \mathrm{~mm}$ and $3.5 \mathrm{~mm}$. Additionally, the geometric size ratio of the experimental members to the actual structural member is $1: 10$.

Standard tensile tests were conducted to measure the steel tube properties. The average static tensile strengths $\left(f_{y}\right)$ of the $2.0 \mathrm{~mm}$ and $3.5 \mathrm{~mm}$ steel tubes are $338 \mathrm{MPa}$ and $323 \mathrm{MPa}$, respectively. The elastic modulus $\left(E_{s}\right)$ of the $2.0 \mathrm{~mm}$ and $3.5 \mathrm{~mm}$ steel tubes are $198 \mathrm{GPa}$ and $201 \mathrm{GPa}$, respectively, and the corresponding elongation values are $21.68 \%$ and $21.57 \%$, respectively. The density of the steel is $7850 \mathrm{~kg} / \mathrm{m}^{3}$. Besides, nine concrete cube blocks with a side length of $150 \mathrm{~mm}$ were made to measure the concrete properties. The average cubic compressive strength $\left(f_{c u}\right)$ of the concrete block is $55 \mathrm{MPa}$, the elastic modulus $\left(E_{c}\right)$ is $35.25 \mathrm{GPa}$, and the density is $2450 \mathrm{~kg} / \mathrm{m}^{3}$.

One gravity-driven impact device, composed of a rigid hammer, a mass block, and a sliding track, was used for generating the impact load, as shown in Fig. 1. The total mass of the impactor $(m)$, including the rigid hammer and mass 
block, was $270 \mathrm{~kg}$. The impact heights of the test were selected to be $3 \mathrm{~m}, 5 \mathrm{~m}$, and $7 \mathrm{~m}$ based on the effective impact length $(H)$ of the slipway, and the corresponding initial impact velocities were $7.67 \mathrm{~m} / \mathrm{s}, 9.90 \mathrm{~m} / \mathrm{s}$, and $11.72 \mathrm{~m} / \mathrm{s}$, respectively. The size of the hammer at the impact contact surface was 30 $\mathrm{mm} * 80 \mathrm{~mm}$. The boundary conditions employed in the test were also shown in Fig. 1. Both ends of the beam were fixed, with the effective support length $\left(L_{E}\right)$ of the member being $900 \mathrm{~mm}$. According to the provisions of BS EN 1991-17:2006 [32], the distance between the impact point and the support was $1.8 \mathrm{~m}$ when the impact action was caused by a derailed train. For general structural members with a length of $6-10 \mathrm{~m}$, the corresponding range of the impact point position was $0.18-0.3$ span. Therefore, the impact point position of the test was located at 2/9 span, as shown in Fig. 1. The impact point was near the support $N$, at a distance of $200 \mathrm{~mm}$; whereas the distance between the centre of the impact point and the support $F$ was $700 \mathrm{~mm}$.

During the test process, the impactor was raised along the slipway to a predetermined impact height, so that the impactor was able to achieve the designed initial impact velocity. A force sensor used to measure the impact load was installed behind the rigid hammer, and the accuracies of the FEAs and theoretical calculations were evaluated by the obtained impact-force time history curve. The dynamic response of the beam was recorded with a highspeed camera, the range of which is shown in Fig. 1. The impact point deflection of the member was extracted from the high-speed camera video.

Table 1

Details of the impact test specimens

\begin{tabular}{|c|c|c|c|c|c|c|c|c|}
\hline Specimen & $m(\mathrm{~kg})$ & $V_{I 0}(\mathrm{~m} / \mathrm{s})$ & $E_{i} \quad(\mathrm{~kJ})$ & $D(\mathrm{~mm})$ & $L_{E}(\mathrm{~mm})$ & $T_{b}(\mathrm{~mm})$ & $f_{y}(\mathrm{MPa})$ & $f_{c u}(\mathrm{MPa})$ \\
\hline YG1 & 270 & 7.67 & 7.94 & 114 & 900 & 2.0 & 338 & 55 \\
\hline YG2 & 270 & 9.90 & 13.23 & 114 & 900 & 2.0 & 338 & 55 \\
\hline YG3 & 270 & 11.72 & 18.54 & 114 & 900 & 2.0 & 338 & 55 \\
\hline YG4 & 270 & 11.72 & 18.54 & 114 & 900 & 3.5 & 323 & 55 \\
\hline YG5 & 270 & 9.90 & 13.23 & 114 & 900 & 3.5 & 323 & 55 \\
\hline
\end{tabular}

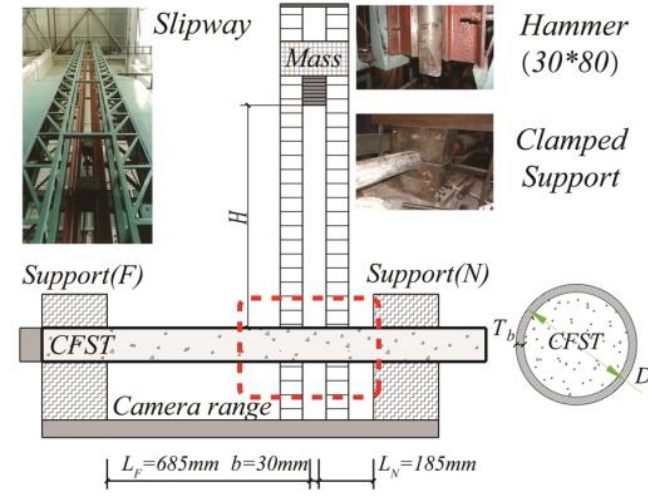

Fig. 1 Test information

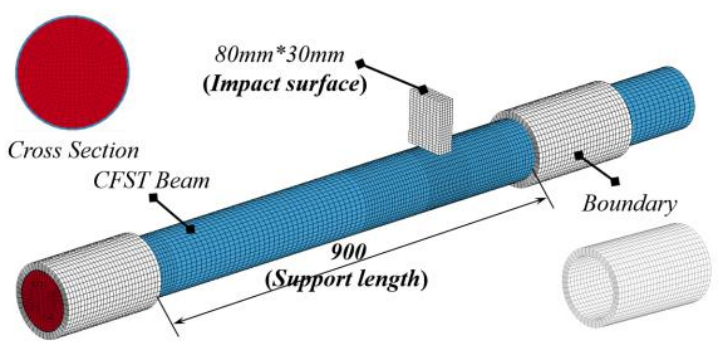

Fig. 2 FEA model

\subsection{Finite element analysis}

\subsubsection{Description of the FEA model}

The deformation modes of CFST beams at the peak value stage were supplemented by the FEAs as well as the change trends of velocity and acceleration at the impact point. The deformation mode is related to the calculation model, with the trend curve of acceleration being a supplementary condition in the analysis calculation.

The drop-weight impact test was simulated for the CFST beams based on the explicit criterion in LS-DYNA [33]. Fig. 2 shows a general FEA model of the CFST member in the simulation analysis. The drop hammer, steel tube, and core concrete were modelled using 8-node solid elements with reduced integration. The mesh convergence study was conducted to determine the appropriate mesh density and ensure the efficiency of the simulation. The maximum size of the solid elements in the simulation models is $11.5 \mathrm{~mm}$.

The material properties of the steel followed the ideal elastic-plastic model (MAT_3 in LS-DYNA), in which the elongation determined the failure strain (FS) of eroding elements. Additionally, the properties of concrete followed the concrete damage model (MAT_72R3 in LS-DYNA) developed by Malvar et al. [34]. This concrete model has also been successfully applied to analyse the behaviours of CFST beams under lateral impact [23,27,31], which includes three independent surfaces (the initial yield surface, the maximum failure surface, and the residual failure surface) to describe the elastic-plastic response of the concrete $[33,34]$.

During the dynamic response process, the strength of steel and concrete increases with the increase of the strain rate, which needs to be considered in FEA and other analysis calculations. The influence of the strain rate on the yield strength of steel is described by the Cowper-Symonds model [35], as shown in Eq. (1):

$$
D I F s=\frac{\sigma_{d y}}{\sigma_{s y}}=\left[1+\left(\frac{\dot{\varepsilon}}{C}\right)\right]^{\frac{1}{P}}
$$

where $\sigma_{d y}$ represents the yield strength of the steel tube under the strain rate $\dot{\varepsilon} ; \quad \sigma_{s y}$ represents the yield strength of a steel tube; and $C$ and $P$ are the strain rate parameters with values $6844 \mathrm{~s}^{-1}$ and 3.91 , respectively $[1,10]$.

The influence of the strain rate on the dynamic compressive strength of concrete can be found in the CEB-FIP model code [36], as shown in Eq. (2)

$$
D I F=\frac{f_{c d}}{f_{c s}}= \begin{cases}\left(\dot{\varepsilon} / \dot{\varepsilon}_{s c}\right)^{1.026 \alpha_{s}} & \dot{\varepsilon} \leq 30 s^{-1} \\ \gamma_{s}\left(\dot{\varepsilon} / \dot{\varepsilon}_{s c}\right) & \dot{\varepsilon}>30 s^{-1}\end{cases}
$$

where $f_{c d}$ represents the dynamic compressive strength of concrete at the strain rate $\dot{\varepsilon}$ within the range of $30 \times 10^{-6} s^{-1}$ to $300 s^{-1} ; f_{c s}$ represents the static compressive strength of concrete at the strain rate $\dot{\varepsilon}_{s c} \quad\left(\dot{\varepsilon}_{s c}=30 \times 10^{-6} s^{-1}\right)$; $\log \gamma_{s}=6.156 \alpha_{s}-2 ; f_{c o}=10 M P a ; \alpha_{s}=\left(5+9 f_{c s} / f_{c o}\right)^{-1}$.

The influence of the strain rate on the dynamic tensile strength of concrete is also given in the CEB-FIP model code [36], as shown in Eq. (3):

$$
D I F=\frac{f_{t d}}{f_{t s}}= \begin{cases}\left(\dot{\varepsilon} / \dot{\varepsilon}_{s t}\right)^{1.016 \delta_{s}} & \dot{\varepsilon} \leq 30 s^{-1} \\ \beta_{s}\left(\dot{\varepsilon} / \dot{\varepsilon}_{s t}\right)^{1 / 3} & \dot{\varepsilon}>30 s^{-1}\end{cases}
$$

where $f_{t d}$ is the dynamic tensile strength of concrete at the strain rate $\dot{\varepsilon}$ within the range of $30 \times 10^{-6} \mathrm{~s}^{-1}$ to $300 \mathrm{~s}^{-1} ; f_{t s}$ is the static tensile strength of concrete at the strain rate $\dot{\varepsilon}_{s t}\left(\dot{\varepsilon}_{s t}=3 \times 10^{-6} s^{-1}\right) ; \log \beta_{s}=7.11 \delta_{s}-2.33$; and $\delta_{s}=1 /\left(10+6 f_{c s} / f_{c o}\right)$.

Both the impact hammer and supports are simplified in the FEA model, as shown in Fig. 2. Specifically, the supports are simplified to hollow cylinders with all degrees of freedom constrained, while the impactor is simplified as a rectangular block. The impact contact surface size and the total mass of the impact block in the FEA model are the same as those in the tests. Both the support and the impact block are rigid bodies, corresponding to the MAT_15 model in LS-DYNA.

The parameters of the CFST beams are consistent with those of the tests. A continuous node mode is used to describe the contact relationship between the 
concrete and the steel tube, while their relative slip is not considered in the FEA model. Automatic node-to-surface contact is adopted as the contact relationship of the CFST beam and the supports as well as between the CFST member and the block, for which the dynamic friction coefficients are 0.2 and 0 , respectively. Additionally, the penalty scale factors, SFS and SFM, are equal to 2.0. The initial impact velocities of the impactor were determined according to the tests. Besides, a stiffness-type hourglass control was used to eliminate the zero-energy modes.

\subsubsection{Verification of the FEA model}

Fig. 3 shows the general FEA result. The dynamic response modes of the CFST beams were bending deformation and fracture, with reasonable CFST beam damage and deformation being obtained via the establishment FEA model.

The impact-force time history curves obtained from the FEAs are shown in Fig. 4. The comparisons between the predicted and experimental peak values $\left(P_{\max }\right)$, plateau values $\left(P_{\text {stable }}\right)$ and load durations $(t)$ of the impact forces $(F)$ are shown in Table 2. The subscripts $F E$ and $T E$ in Table 2 refer to the FEA and the experimental results, respectively. The mean values of $P_{\max , F E} / P_{\max , T E}$, $P_{\text {stable }, F E} / P_{\text {stable }, T E}$ and $t_{F E} / t_{T E}$ ratios are $0.97,1.05$ and 1.01 , respectively, and the corresponding standard deviations are $0.049,0.037$, and 0.061 . The maximum deflections of the impact point ( $W_{b \max }$ ) obtained from the FEAs and the tests are also summarised in Table 2. The mean value and standard deviation of the $W_{b \max , F E} / W_{b \max , T E}$ ratio are 1.01 and 0.054 , respectively. Therefore, the results of the dynamic response of CFST beams obtained from the FEAs are consistent with those from the 2/9 span tests.

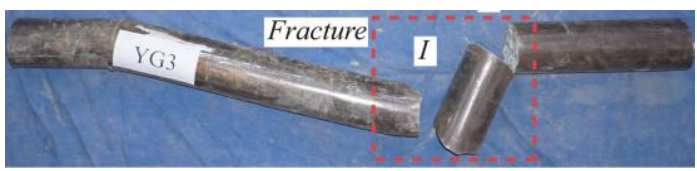

(a) Test Result

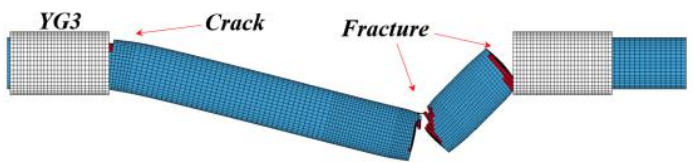

(b) FEA Result

Fig. 3 Damage condition

Table 2

Summary of the FE simulation results

\begin{tabular}{|c|c|c|c|c|c|c|c|c|c|c|c|c|}
\hline \multirow{2}{*}{ Specimen } & \multicolumn{3}{|c|}{$P_{\max }(\mathrm{kN})$} & \multicolumn{3}{|c|}{$P_{\text {stable }}(\mathrm{kN})$} & \multicolumn{3}{|c|}{$W_{b \max }(\mathrm{mm})$} & \multicolumn{3}{|c|}{ Total duration $t(\mathrm{~ms})$} \\
\hline & FEA & TEST & $\mathrm{FE} / \mathrm{TE}$ & FEA & TEST & $\mathrm{FE} / \mathrm{TE}$ & FEA & TEST & FE/TE & FEA & TEST & $\mathrm{FE} / \mathrm{TE}$ \\
\hline YG1 & 370.3 & 410.9 & 0.90 & 210.6 & 193.8 & 1.09 & 30.9 & 32.2 & 0.96 & 14.0 & 13.3 & 1.05 \\
\hline YG2 & 469.0 & 449.6 & 1.04 & 193.2 & 186.1 & 1.07 & 93.7 & 91.4 & 1.03 & 44.4 & 42.5 & 1.04 \\
\hline YG3 & 529.3 & 527.1 & 1.00 & 199.2 & 201.6 & 0.96 & \multicolumn{3}{|c|}{ Fracture } & \multicolumn{3}{|c|}{ Fracture } \\
\hline YG4 & 619.4 & 651.2 & 0.95 & 312.4 & 286.8 & 1.09 & 49.5 & 49.5 & 1.00 & 12.6 & 13.1 & 0.96 \\
\hline YG5 & 517.3 & 542.6 & 0.95 & 309.3 & 294.6 & 1.05 & 35.5 & 33.3 & 1.06 & 11.3 & 11.7 & 0.97 \\
\hline Mean Error & & & 0.97 & & & 1.05 & & & 1.01 & & & 1.01 \\
\hline Std. Dev. & & & 0.049 & & & 0.037 & & & 0.054 & & & 0.061 \\
\hline
\end{tabular}

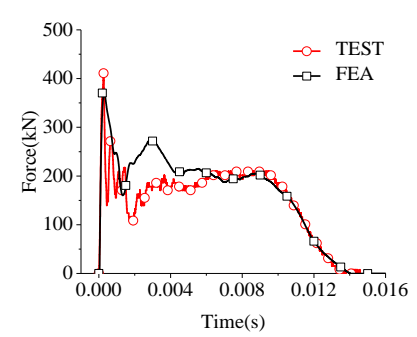

(a) YG1

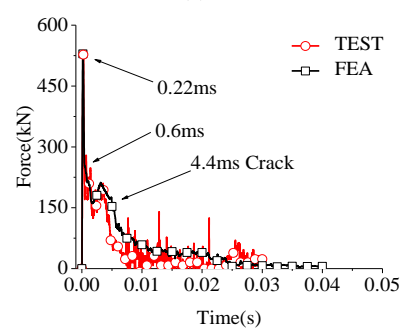

(c) YG3

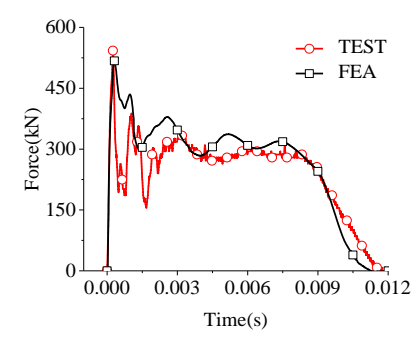

(e) YG5

Fig. 4 Impact-force time history curves

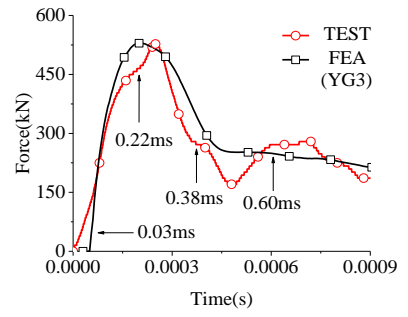

(a) Impact force

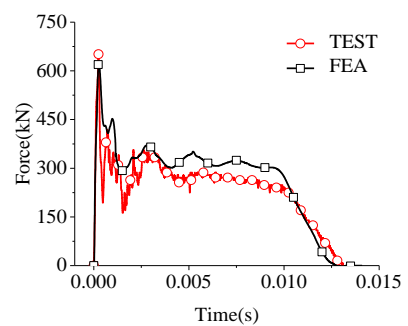

(b) YG4
(1)

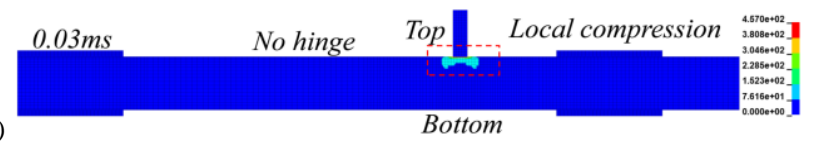

(2)

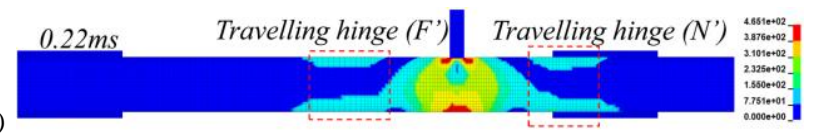

(3)

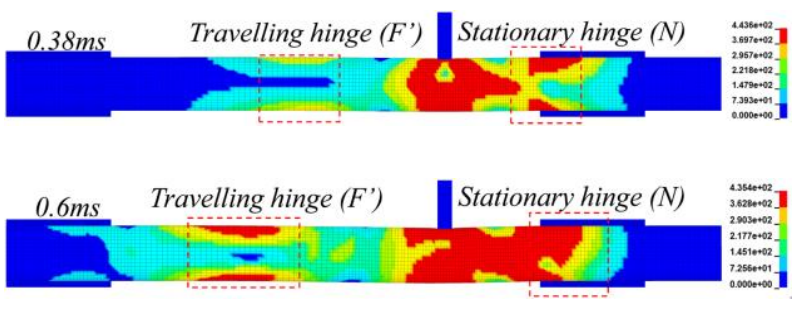

(b) Stress distribution 


\subsection{Deformation mode}

Fig. 5 shows the propagation process of stress waves at the peak value stage, which is applied to analyse the force mechanism of CFST members. From the Von-Mises stress distributions of the beam (YG3), there are two deformation modes for CFST beams at the peak value stage which are the local compression mode and the local bending deformation mode.

The local compression stage is shown in Fig. 5 (b-1). At this stage, the stress wave propagated from the top to the bottom point, and the stress value at the bottom point of the CFST member was always zero. From this phenomenon, it is considered that the bottom of the CFST member cross-section remains stationary, and the whole deformation of the cross-section does not occur. Therefore, only local compressive deformation occurs in CFST members at this stage. After the stress wave spreads to the bottom of the CFST beam, the member cross-section exhibits the bending deformation.

The bending deformation stage is shown in Fig. 5 (b-2) to (b-4). The main feature of this stage is that there are two travelling stress-concentrated regions (i.e., travelling hinges) outside the impact point. The middle of the stressconcentrated region displayed a low-stress level, while the top and bottom of the region displayed high- stress levels; which is a typical bending stress distribution. Therefore, it was determined that the deformation mode of the CFST beam is a bending mode. The stress distribution also proved that the deformation of the CFST beam is local since there were stress-less regions between the supports and the stress-concentrated regions. The stressconcentrated regions gradually extended from the impact area to the constraints, as shown in Fig. 5 (b-2) to (b-4), a process that can be described by the travelling hinge theory [14-16, 37]. The stress-concentrated region is similar to the travelling hinge, with the stress level of the travelling hinge increasing during its travelling process, resulting in it eventually reaching a plastic state from an elastic state, as seen in Fig. 5 (b-4). Thus, the elastoplastic behaviour of CFST beams is an additional factor that requires consideration in analysis calculations.

\subsection{Velocity and acceleration}

Fig. 6 displays the velocity time history and acceleration time history curves for the YG3 case, with $W_{b}, V_{b}$ and $a_{b}$ as the displacement, velocity and acceleration variables of the CFST member at the impact point, respectively. Additionally,. $W_{I}, V_{I}$ and $a_{I}$ are the displacement, velocity and acceleration variables of the impactor, respectively. The above parameters are also marked in Fig. 6 (c).

The impact velocity (Velocity) versus time (Time) curves are showed in Fig. 6(a), including $V_{I}$ and $V_{b}$. From the $V_{I}$ curve, the velocity of the impactor decreases continuously at the peak value stage which indicates that the impactor is always in the state of deceleration. In contrast, the $V_{b}$ curve witnesses an increase during the initial period, which indicates that the CFST beam is in the state of acceleration, then it falls gradually. Thus, the peak value stage can be further divided into the acceleration process $(O L V)$ and the deceleration process (after point $V$ ) based on the state of the CFST beam. The demarcation point of the two processes is represented by point $V$, as shown in Fig. 6 (a). From the $V_{b}$ curve, It is also observed the fact that the acceleration process is characterized by the approximate linear increment. Based on this feature, it can be assumed that the value of $a_{b}$ is approximately a constant during the acceleration process. Besides, as the $V_{b}$ and $V_{I}$ curves stay close and share the similar trend in the deceleration process, it can be assumed that $V_{I} \equiv V_{b}$ in this process, which is also a general supplementary condition in the analysis calculations [15-16, 27-30], while not suitable at the peak value stage.

The supplementary condition of the acceleration process is suggested to be the simplified acceleration time history curve (i.e., the simplified trend curve), as shown in Fig. 7. The simplified trend curve in the acceleration process can be divided into three stages in which: $O L$ represents the local compression stage, $L V$ indicates the constant acceleration stage of bending deformation, and $V A$ denotes the transition stage. Point $O$ is the initial time of the impact process; point $L$ is defined as the end time of the local compression process; point $V$ is the time when $V_{I}=V_{b}$ for the first time (although $a_{I} \neq a_{b}$ at this time), and point $A$ is the time when $V_{I} \equiv V_{b} \quad\left(V_{I}=V_{b}\right.$ and $\left.a_{I}=a_{b}\right)$. The constant acceleration stage is the main component of the simplified trend curve, corresponding to the linear change process of the $V_{b}$ curve. The function of the local compression stage is to determine the parameters of the simplified curve. Since the CFST beam was already in the constant acceleration state when the local compression stage ended ( $L$ moment) (Fig. 6 [a] and $[\mathrm{b}]$ ), time and the value of $a_{b}$ at the $L$ moment were used as the representative values to determine the curve. Finally, the transition stage was applied to ensure that $V_{I} \equiv V_{b}$ at $A$ time. Point $V$ and point $A$ were determined by the relative motion states of the impactor and CFST beam.

The ideal simplified trend curve and the corresponding velocity time history curve are also displayed in Fig. 6(a) and (b). Compared with the FEA result ( $a_{b}$ FEA), although the trend of the simplified curve at the VA stage is slightly different from that of the FEA result, the general trends of the two curves in the acceleration process appear to be similar.

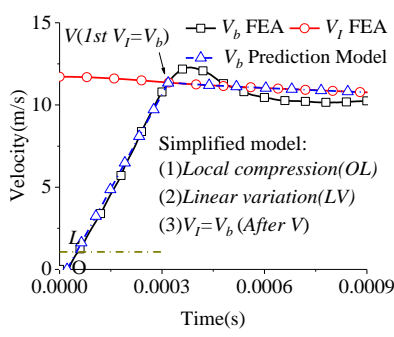

(a) Velocity time history curve

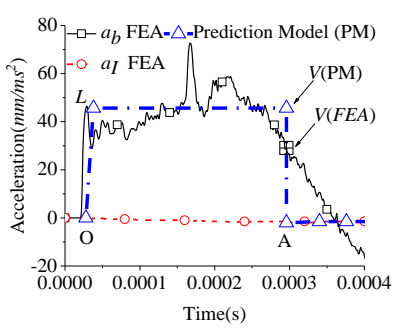

(b) Acceleration time history curve

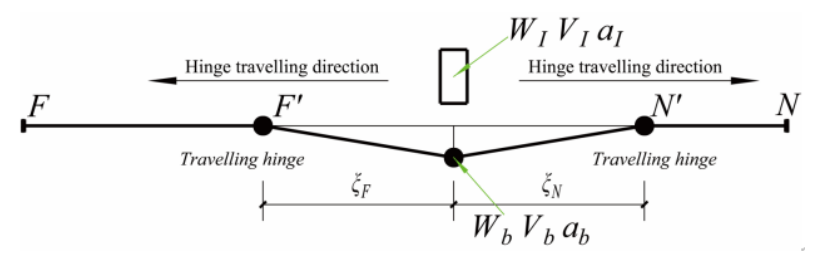

(c) General impact process

Fig. 6 Velocity and acceleration

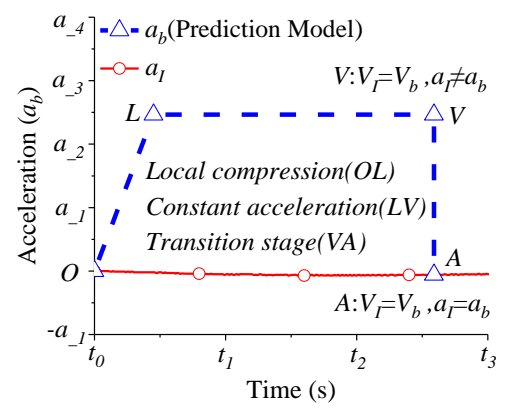

Fig. 7 Simplified acceleration curve

\section{Analysis method of the peak value stage}

\subsection{Analysis process}

There are two stages in the analysis and calculation process: local compression stage and bending deformation stage. The calculation of the local compression stage was performed to predict the parameters of the simplified trend curve (prediction model), as shown in Figure 7. Then, the bending deformation stage could be calculated based on the travelling hinge theorem, wherein the prediction model provides the supplementary condition for solving the equations.

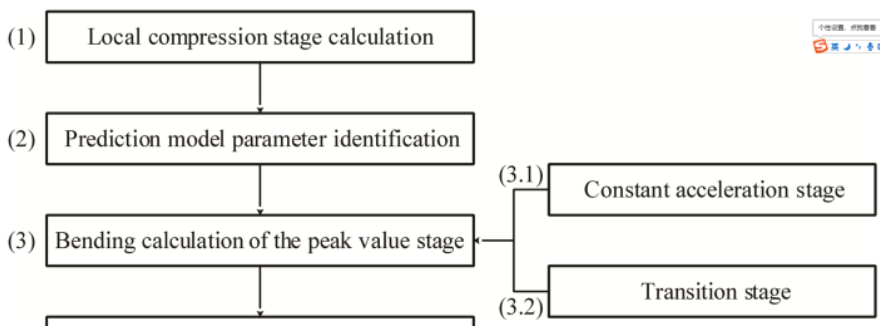

(4)

Calculation after the peak value stage

Fig. 8 Calculation process

The calculation process was divided into four stages according to the proposed prediction model, as shown in Fig. 8.

Step 1: Local compression stage calculation.

Step 2: Prediction model parameter identification.

Step 3: Bending deformation calculation at the peak value stage (based on the prediction model). 
Step 4: Bending deformation calculation after the peak value stage (based on the $V_{I} \equiv V_{b}$ assumption).

On the basis of the prediction model, Step 3 can also be subdivided into the constant acceleration stage (Step 3.1) and the transition stage (Step 3.2).

\subsection{Prediction of the acceleration curve}

\subsubsection{Calculation of the local compression process}

The parameters of the prediction model were determined by the value of $a_{b} \quad\left(a_{b L}\right)$ and time $\left(t_{L}\right)$ at the end of the local compression stage. Therefore, the $a_{b}$ curve of the peak value stage could be predicted by the calculation of the local compression stage.

The propagation process of the impact at the local compression stage $(O L)$ is shown in Fig. 9, which shows that the stress wave propagates from the contact point $(C P)$ to the bottom of the beam $(B P)$, and before it reaches point $B P$, the bottom of the beam is in a static and stress-less state. Thus, it can be concluded that the beam cannot generate bending deformation, and the local compression model is recommended for calculation during this process.

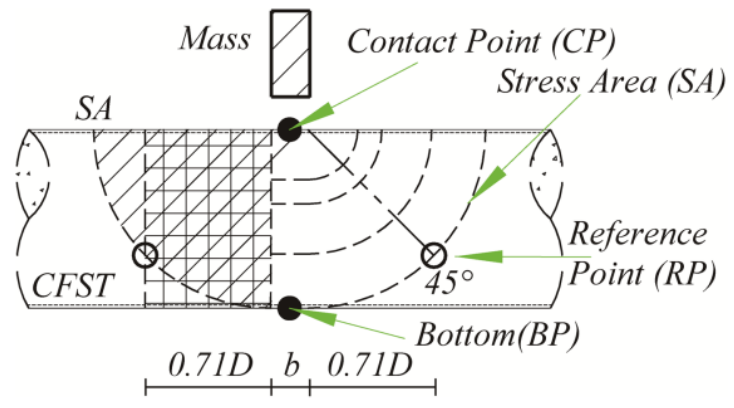

Fig. 9 Local compression model

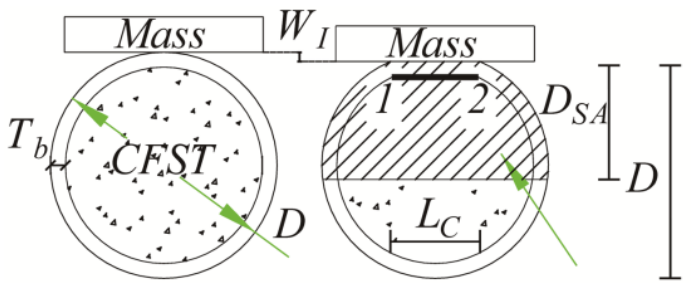

Stress Area

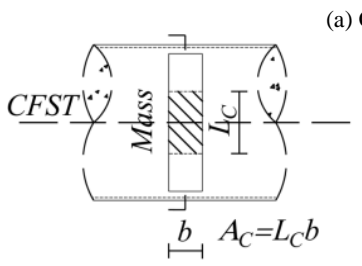

(b) Contact area

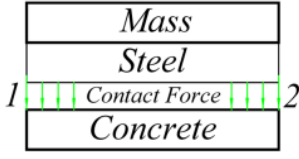

(c) Contact force
Fig. 10 Calculation of the local compression process

Fig. 10 displays the calculation model of the local compression stage. The contact force is assumed to be controlled by the core concrete material, as shown in Fig. 10 (c). The force balance equation between steel and concrete was established, as given in contact mechanics [38]:

$m a_{I}+D I F \times f_{c c} \times A_{C}=0$

where $A_{C}$ is the contact area; $f_{c c}$ is the concrete strength with consideration to the lateral confining pressure; DIF is the dynamic increase factor of the concrete material given in the CEB90 model code[36].

The value of $f_{c c} \quad[39,40]$ is calculated by Eq.(5)

$$
f_{c c}=f_{c}+k \sigma_{3}
$$

where $f_{c}$ is the characteristic concrete strength, taken as 0.67 of the cubic strength of concrete for normal-strength concrete $[1,10] ; k$ is an empirical coefficient $[39,40]$; and $\sigma_{3}$ is the confining pressure around the concrete core, which can be estimated according to the local transverse strain of the concrete.

$\sigma_{3}=E_{c} \varepsilon_{3} \leq f$ where $E_{c}$ is the elastic modulus of concrete; $\varepsilon_{3}$ is the transverse strain of concrete at the impact point region; the transverse direction is the axial direction of the beam. The value of $\varepsilon_{3}$ can be calculated by the definition of Poisson's ratio, as shown in Eq. (7):

$v=\frac{\varepsilon_{3}}{\varepsilon_{\mathrm{c} 3}}$

where $v$ represents Poisson's ratio and $\varepsilon_{c 3}$ is the local compressive strain of concrete. The value of $\varepsilon_{c 3}$ is conservatively estimated by Eq. (8).

$\varepsilon_{c 3}=\frac{W_{I}}{\alpha\left(D-2 T_{b}\right)}$

where $D$ is the diameter of the beam; $T_{b}$ is the thickness of the steel tube; $W_{I}$ is the displacement of the impactor. Additionally, $\alpha$ is the stress distribution coefficient with a suggested value of 0.71 .

$D-2 T_{b}$ in Eq. (8) is a conservative approximation of $D_{S A} . D_{S A}$ is the height of the stress area, as shown in Fig. 10 (a), and $\alpha$ is the coefficient related to the stress distribution. From Fig. 9, the shape of the stress distribution in CFST members is approximately semi-circular. Thus, the impact point region with width $b$ is subjected to the transverse constraint of the surrounding concrete. Moreover, the transverse constraint level of concrete at different section heights is not the same. If the effect of transverse constraint is ignored, $\alpha=1$. When considering this effect, a reference point (i.e., point $R P$ ) can be used to estimate the average influence of the transverse constraint. The recommended point $R P$ is the intersection point between the $45^{\circ}$ line and the stress area edge, as shown in Fig. 9. Thus, the value of $\alpha$ is $0.71\left(\sin 45^{\circ}\right)$. Additionally, the initial state of the bending deformation stage can also be obtained from the point $R P$. A rectangular stress area determined by the reference point can be equivalent to the semi-circular stress area, as seen in Fig. 9.

Then, the local compression strain rate $\left(\varepsilon^{\prime}\right)$ used to estimate the DIF can also be calculated by Eq. (9).

$\varepsilon^{\prime}=\frac{V_{I}}{\alpha\left(D-2 T_{b}\right)}$

where $V_{I}$ is the velocity of the impactor.

Besides, $A_{C}$ is the contact area, and its value is calculated by Eq. (10):

$A_{C}=L_{C} b$

where $b$ is the width of the hammer; $L_{C}$ is the contact length displayed in Fig. 10(b). For circular cross-sections, $L_{C}$ is calculated based on geometric relationships [38]:

$L_{C}=2 \sqrt{W_{I} D}$

\subsubsection{Termination time of local compression stage}

The local compression stage was terminated when the stress wave reached point $B P$. It was assumed that $D_{S A}$ in Fig. 10(a) represented the maximum vertical distance between the stress area and the contact point. Thus, when $D_{S A}=D$, the local compression stage was terminated. At the time of $D_{S A}=D$, the vertical propagation distances of the stress wave in the steel and concrete are $2 T_{b}$ and $D-2 T_{b}$, respectively. Therefore, according to the formula for the elastic stress wave velocity [41], the termination time of the local compression stage $\left(t_{L}\right)$ can be estimated as:

$t_{L}=\frac{2 T_{b}}{\sqrt{E_{s} / \rho_{s}}}+\frac{D-2 T_{b}}{\sqrt{E_{c} / \rho_{c}}}$

where $E_{s}$ and $E_{c}$ are the elastic modulus values of steel and concrete, respectively; $\rho_{s}$ and $\rho_{c}$ are the densities of steel and concrete, respectively. 3.2.3 Acceleration prediction

The stress area $(S A)$ of the CFST member at time $L$ (i.e., the termination time of the local compression stage) is shown in Fig. 9. According to the reference point $(R P)$, the empirical acceleration distribution is shown in Fig. 11. In this empirical distribution, the acceleration value of the impact point region 
with width $b$ is $a_{b}$, and the position of zero acceleration point is $0.71 \mathrm{D}$ away from the boundary of the impact point region. It is assumed that the acceleration distribution is linear between the zero acceleration point and the edge of the impact point area.

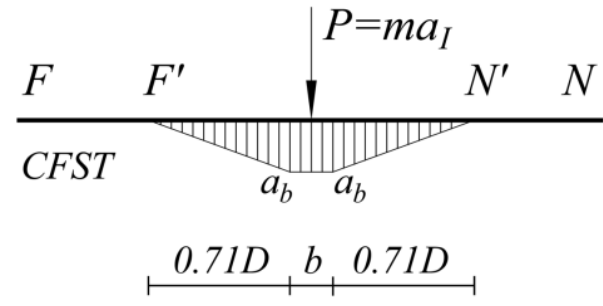

Fig. 11 The initial distribution of the acceleration during the bending stage

Therefore, the acceleration value of the beam impact point at time $L\left(a_{b L}\right)$ is calculated as follows:

$a_{b L}=-\frac{m a_{I L}}{\rho_{l}(b+0.71 D)}$

where $\rho_{l}$ is the beam mass per unit length; $a_{I L}$ is the acceleration of the impactor at time $L$ obtained from Eq. (4).

Furthermore, the velocity of the beam impact point ( $\left.V_{b L}\right)$ at time $L$ was obtained by momentum conservation:

$V_{b L}=\frac{m\left(V_{I 0}-V_{I L}\right)}{\rho_{l}(b+0.71 D)}$

where $V_{I L}$ is the velocity of the impactor at time $L$ obtained from Eq. (4)

The average deflection of the beam impact point at time $L\left(W_{b L}\right)$ can be calculated using Eq. (15).

$W_{b L}=0.5 V_{b L} t_{L}$

In Eq. (13), $a_{b}$ is a positive value, indicating that the velocity of the member gradually increases, whereas $a_{I}$ is always negative, indicating that the impactor velocity continues to decrease.

\subsection{Bending stage calculation}

\subsubsection{Bending equilibrium equation}

The diagram used in the calculation of the impact process based on the travelling hinge model is shown in Fig. 6(c), in which $F^{\prime}$ and $N^{\prime}$ represent the travelling hinges. When a travelling hinge reaches the supported end of the beam, it immediately transforms into a stationary hinge. Equations for the travelling hinge model based on the assumption that $V_{I} \equiv V_{b}$ has been provided in the literature $[15,16,37]$. If the impactor and the member are independent, the original equation can be altered to Eqs. (16)-(18).

$m a_{I}+\frac{1}{2} \rho_{l} a_{b}\left(\xi_{F}+\xi_{N}\right)+\frac{1}{2} \rho_{l} V_{b}\left(\xi_{F}^{\prime}+\xi_{N}^{\prime}\right)+Q_{F}+Q_{N}=0$

$M_{F}+M_{I}=\frac{\rho_{l} a_{b} \xi_{F}^{2}}{6}+\frac{\rho_{l} V_{b} \xi_{F} \xi_{F}^{\prime}}{3}+Q_{F} \xi_{F}$

$M_{N}+M_{I}=\frac{\rho_{l} a_{b} \xi_{N}^{2}}{6}+\frac{\rho_{l} V_{b} \xi_{N} \xi_{N}^{\prime}}{3}+Q_{N} \xi_{N}$

where $\xi_{F}$ and $\xi_{N}$ represent the location of the travelling hinges; $\xi_{N}{ }^{\prime}$ and $\xi_{F}^{\prime}$ represent the corresponding travelling hinge velocities; $M_{I}$ is the bending moment value of the stationary hinge at impact point $I ; M_{N}$ and $M_{F}$ are the bending moment values of the corresponding travelling hinges; $Q_{N}$ and $Q_{F}$ are the shear force values of hinges $N$ and $F$, respectively; and the subscripts $F$ and $N$ represent the supports corresponding to the travelling hinges $F^{\prime}$ and $N^{\prime}$
$L_{N}$ and $L_{F}$ denote the distance from impact point $I$ to the supports $N$ and $F$, respectively. Before a travelling hinges reaches the support $\left(\xi_{N}<L_{N}\right.$ or $\left.\xi_{F}<L_{F}\right)$, the travelling hinge shear force is ignorable $\left(Q_{N}=0\right.$ or $\left.Q_{F}=0\right)$; however, the travelling hinge velocity is not zero $\left(\xi_{N}{ }^{\prime} \neq 0\right.$ or $\left.\xi_{F}{ }^{\prime} \neq 0\right)$. Conversely, if $\xi_{N}=L_{N}$ or $\xi_{F}=L_{F}, Q_{N(F)} \neq 0$ and $\xi_{N(F)}{ }^{\prime}=0$.

\subsubsection{Elastoplasticity of a travelling hinge}

As steel and concrete are both elastic-plastic materials, the travelling hinge of a CFST beam is not rigid-plastic. Eqs. (19) and (20) illustrate an approximation method for estimating the elastoplastic deformation of a travelling hinge:

$M_{N}=M_{I}=K \theta_{N} \leq M_{y}$

$M_{F}=K \theta_{F} \leq M_{y}$

$\theta_{N}=W_{b} / \xi_{N}$

$\theta_{F}=W_{b} / \xi_{F}$

where $M_{y}$ is the dynamic yield bending moment of the beam; $\theta_{N}$ and $\theta_{F}$ are the rotation angles of the travelling hinges; and $K$ is the dynamic rotational stiffness.

$K=D I F_{\theta} \times K_{\theta}$

where $D I F_{\theta}$ is the dynamic increase factor related to the rotational velocity of the hinge, and $K_{\theta}$ is the static rotational stiffness calculated as follows:

$$
K_{\theta}=\frac{K_{\phi}}{l_{p}}
$$

where $K_{\phi}$ is the flexural rigidity of a CFST beam according to the AIJ1997 code [42], and $l_{p}$ is the equivalent length of the hinge region with a value of $0.5 D$.

$K_{\phi}=E_{S} I_{S}+0.2 E_{C} I_{C}$

where, $I_{S}$ and $I_{C}$ are the inertia moments of the steel tube and core concrete sections, respectively.

Eqs. (19) and (20) are optimisations of the $M_{N}=M_{I}=M_{F}=M_{y}$ assumption (i.e., the rigid-plastic model). The $M_{N}=M_{I}$ assumption is based on both the 2/9 span tests and FEA results, as shown in Fig. 3 and Fig. 5. Similar estimation methods of the $\theta$ value can also be found in the calculation of $\mathrm{Qu}$ [27].

Since the steel tube provides the main flexural capacity, $D I F_{\theta}$ is estimated as follows:

$D I F_{\theta}=1+\left(\frac{\theta^{\prime}}{C}\right)^{\frac{1}{P}}$

where $C$ and $P$ are the strain rate parameters: $\mathrm{C}=6844$ and $\mathrm{P}=3.91[1,7]$ Additionally, $\theta^{\prime}$ is the rate of the rotation angle [23].

$\theta^{\prime}=\frac{V_{b}}{\xi_{N}}$

Then, the dynamic yield bending moment of the beam $\left(M_{y}\right)$ can be calculated as follows:

$M_{y}=D I F_{\theta} \times M_{u}^{s}$

where $M_{u}^{s}$ is the static yield bending moment of the beam that can be calculated by the formula presented by Han [43].

3.3.3 Calculation of bending stage

(1) Step 3.1 
The unknown variables of the three equilibrium equations (16)-(18) include $W_{I}, W_{b}, \xi_{F}$ and $\xi_{N}$. The prediction model provided the acceleration value of the beam $\left(a_{b}\right)$ to determine its deflection $\left(W_{b}\right)$. Thus, the equations can be solved.

The initial travelling hinge position ( $\left.\xi_{0}\right)$ is shown in Figs. 9 and 11.

$\xi_{0}=0.71 D$

The supplementary condition for the equilibrium equations is as follows:

$a_{b}(t)=a_{b L}$

The calculation process begins at time $L$ (i.e., the termination time of the local compression stage), and the termination condition of the calculation process is the first occurrence of $V_{I}=V_{b}$.

(2) Step 3.2

The transition stage (VA) in the prediction model is shown in Fig. 7, with the times corresponding to point $V$ and point $A$ being equal. During the calculation, the basic assumption is $a_{I}=a_{b}$, and the parameters other than $Q_{N}$, $Q_{F}, \xi_{N}{ }^{\prime}$ and $\xi_{F}{ }^{\prime}$ maintain their values at $V$ time. By introducing $a_{I}=a_{b}$ into Eqs. (16)-(18), the acceleration value corresponding to point $A$ can be obtained.

(3) Step4

The deformation mode of the beam after the peak value stage is also a bending-type. Hence, Eqs. (16)-(18) can still be applied for the calculation of this stage. However, the supplementary condition changes from the prediction model to the equation $V_{I} \equiv V_{b}$.

\subsection{Analysis Results}

The dynamic response of the CFST beam at the peak value stage under lateral impact was predicted using the proposed analysis method, and the accuracy of which was then verified by the $2 / 9$ span tests employed in this study and five other $1 / 2$ span tests $[1,10]$. The rationality of the calculated results was evaluated by the acceleration and impact-force time history curves.

\subsubsection{Acceleration time history curve}

Fig. 12 presents the acceleration time history curve at the impact point $I$ obtained from the prediction model. The calculated acceleration value of the beam in the constant acceleration stage was $a_{b, L V}$, and the results are summarized in the table of Fig. 12. The corresponding average value of FEA was assigned as $a_{b, F E A m e a n}$. As shown in the table of Fig. 12, the mean value of the $a_{b, L V} / a_{b, \text { FEAmean }}$ ratio was 0.987 , and its standard deviation was 0.0504 . The maximum calculation error appeared in the YG1 case, for which the value of

the $a_{b, L V} / a_{b, \text { FEAmean }}$ ratio was 0.899 . This error also led to a low calculated value of impact force in the YG1 case.

The shortcomings of the prediction model can be observed clearly in Fig. 12. The FEA results show that the impact point acceleration of the CFST beam decreases after the constant acceleration stage (point $V$ ), and gradually approaches the acceleration value of the impactor. However, the prediction model (VA) assumes that this process is completed immediately. The calculation error in the acceleration at this stage is evident, and its influence was discussed in the following section according to the impact-force time history curves.

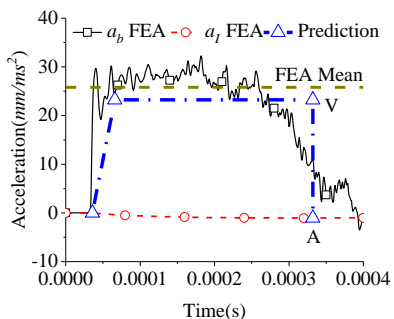

(a) YG1

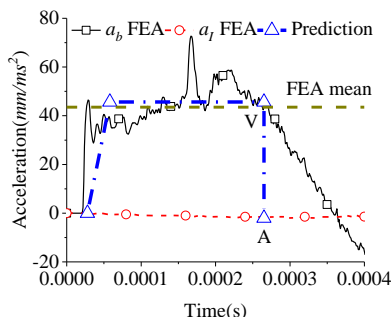

(c) YG3

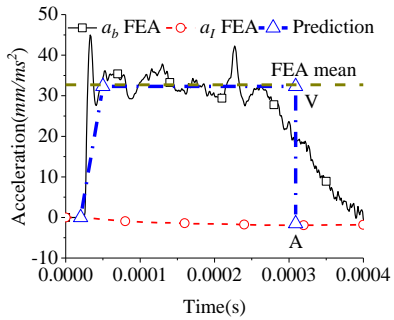

(e) YG5

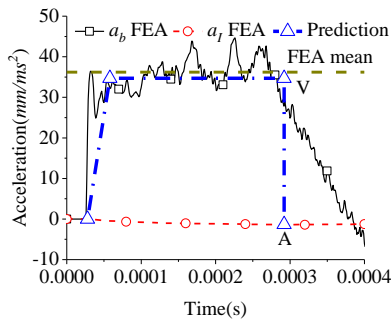

(b) $\mathrm{YG} 2$

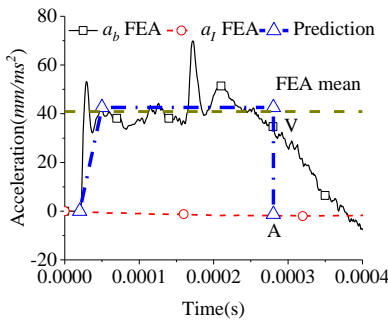

(d) YG4

\begin{tabular}{|c|ccc|}
\hline \multirow{2}{*}{ Specimen } & \multicolumn{3}{|c|}{$a_{\Delta, L V}\left(\mathrm{~mm}^{\mathrm{m}} / \mathrm{ms}^{2}\right)$} \\
\cline { 2 - 4 } & THY & FEA & THFE \\
\hline YG1 & 23.2 & 25.8 & 0.899 \\
YG2 & 34.7 & 36.2 & 0.959 \\
YG3 & 45.6 & 43.5 & 1.048 \\
YG4 & 42.6 & 40.9 & 1.042 \\
YG5 & 32.3 & 32.7 & 0.988 \\
\hline Mean error & 0.987 & Std. dev. & 0.050 \\
\hline
\end{tabular}

(f) Summary

Fig. 12 Calculation results of prediction models

Table 3

Details of the analysis calculations

\begin{tabular}{|c|c|c|c|c|c|c|c|c|c|c|c|c|c|}
\hline Specimen & $\begin{array}{c}m \\
(\mathrm{~kg})\end{array}$ & $\begin{array}{c}V_{I 0} \\
(\mathrm{~m} / \mathrm{s})\end{array}$ & $\begin{array}{c}D \\
(\mathrm{~mm})\end{array}$ & $\begin{array}{c}T_{b} \\
(\mathrm{~mm})\end{array}$ & $\begin{array}{c}f_{c} \\
(\mathrm{MPa})\end{array}$ & $k^{[39,40]}$ & $\begin{array}{c}E_{c} \\
(\mathrm{MPa})\end{array}$ & $\begin{array}{c}f_{y} \\
(\mathrm{MPa})\end{array}$ & $\begin{array}{c}M_{y} \\
(\mathrm{kN} \cdot \mathrm{m})\end{array}$ & $\begin{array}{c}\text { Impact } \\
\text { point }\end{array}$ & $\begin{array}{c}P_{\max , T H} \\
(\mathrm{kN})\end{array}$ & $\begin{array}{c}P_{\max , T E} \\
(\mathrm{kN})\end{array}$ & $\mid$ I-TH/TE $\mid$ \\
\hline YG1 & 270 & 7.67 & 114 & 2 & 36.85 & 4.1 & 35250 & 338 & 9.63 & 2/9span & 364.3 & 410.9 & $11.33 \%$ \\
\hline YG2 & 270 & 9.90 & 114 & 2 & 36.85 & 4.1 & 35250 & 338 & 9.63 & $2 / 9$ span & 436.4 & 449.6 & $2.93 \%$ \\
\hline YG3 & 270 & 11.7 & 114 & 2 & 36.85 & 4.1 & 35250 & 338 & 9.63 & 2/9span & 498.4 & 527.1 & $5.44 \%$ \\
\hline YG4 & 270 & 11.7 & 114 & 3.5 & 36.85 & 4.1 & 35250 & 323 & 15.36 & 2/9span & 636.3 & 651.2 & $2.28 \%$ \\
\hline YG5 & 270 & 9.90 & 114 & 3.5 & 36.85 & 4.1 & 35250 & 323 & 15.36 & $2 / 9$ span & 565.3 & 542.6 & $4.18 \%$ \\
\hline $\mathrm{CC} 1^{[1]}$ & 465 & 9.21 & 180 & 3.65 & 50.32 & 3 & 36800 & 247 & 35.26 & $1 / 2$ span & 870.0 & 811.1 & $7.27 \%$ \\
\hline $\mathrm{CC} 2^{[1]}$ & 920 & 6.40 & 180 & 3.65 & 50.32 & 3 & 36800 & 247 & 35.26 & $1 / 2$ span & 666.3 & 624.8 & $6.65 \%$ \\
\hline $\mathrm{CC} 3^{[1]}$ & 465 & 9.67 & 180 & 3.65 & 50.32 & 3 & 36800 & 247 & 35.26 & $1 / 2$ span & 901.9 & 787.9 & $14.47 \%$ \\
\hline $\mathrm{DBF} 14^{[10]}$ & 230 & 3.90 & 114 & 1.7 & 32.63 & 4.1 & 32500 & 232 & 6.11 & $1 / 2$ span & 148.2 & 160.5 & $7.66 \%$ \\
\hline $\mathrm{DBF} 17^{[10]}$ & 230 & 4.40 & 114 & 1.7 & 32.63 & 4.1 & 32500 & 232 & 6.11 & $1 / 2$ span & 175.5 & 168.5 & $4.18 \%$ \\
\hline Mean Error & & & & & & & & & & & & & $6.64 \%$ \\
\hline Std. Dev. & & & & & & & & & & & & & 0.035 \\
\hline
\end{tabular}


Compared with the impact force peak values from the verification tests $\left(P_{\max , T E}\right)$, the mean error of the analysis calculation $\left(P_{\max , T H}\right)$ was $6.64 \%$, and the standard deviation was 0.035 . One of the cases exhibiting a larger error was YG1, in which the calculation value was $11.33 \%$ lower than the experimental value. The reason for this error may be that the influence of the steel tube was not considered in determining the parameters of the prediction model in Eq. (4). Therefore, the calculated results of beam acceleration $\left(a_{b}\right)$ and the impact force were lower than those of the test. In addition, the greatest calculation error occurred in the case of $\mathrm{CC} 3$, in which the calculated value was $14.47 \%$ higher than the test value. A particular case led to this deviation, which involved the impact force peak values of the tests decreasing with rising impact velocity, as seen in $\mathrm{CC} 1$ and $\mathrm{CC} 3$. Although the theoretical method cannot reasonably describe this phenomenon, it can be inferred that it may be related to local damage of the CFST beam. Additionally, it can be further found from the impact-force time history curves that the VA process in the prediction model is acceptable, as shown in Fig. 13. This approximation method does not yield significant errors in the calculation results.

After the $A$ time in Fig. 13, the impact-force platform value can be calculated based on the $V_{I} \equiv V_{b}$ assumption, and the calculation results consistent with the tests were obtained from the original travelling hinge theorem. However, since the $V_{I} \equiv V_{b}$ assumption was employed, the fluctuations of the impact force curves could not be described. The calculation process employed in this paper terminated after all the travelling hinges transformed into stationary hinges ( $L_{F}=\xi_{F}$ ). It can be found from the curves after A time that the actual constraint length of the CFST beam at the early platform stage may be less than the distance from the impact point to the supports.

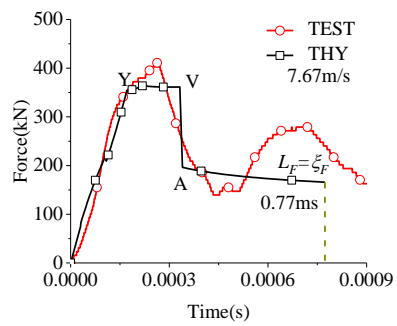

(a) YG1

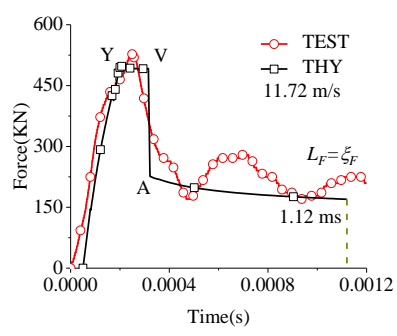

(c) YG3

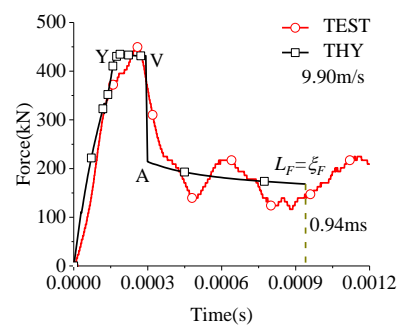

(b) YG2

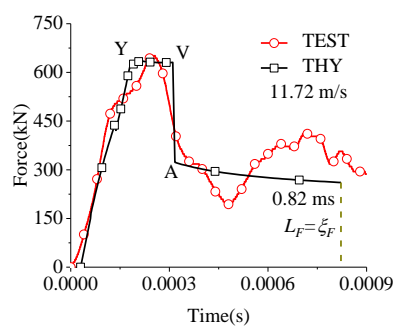

(d) YG4

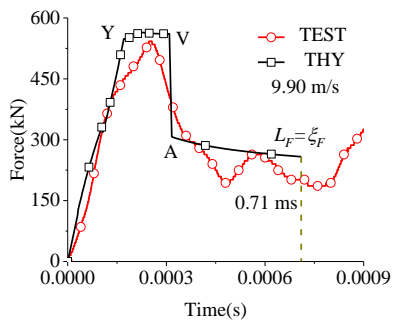

(e)YG5

Fig. 13 Analysis calculation results

\section{Conclusion}

In this paper, an analysis method was presented to predict the dynamic response of CFST beams under the lateral impact process at the peak value stage. The rationality of the method was verified by the acceleration time history curve of FEAs and the impact-force time history curve of lateral impact tests. The following conclusions were obtained from the research of this paper.

(1) A simplified trend curve of the acceleration at the impact point of a CFST beam is proposed based on the FEA results. The curve can be a new supplementary solution condition in the calculation of the peak value stage. The simplified trend curve divides the peak value stage into the local compression stage, the constant acceleration bending stage, and the transition stage.
(2) The parameters of the simplified trend curve can be predicted by the calculation of the local compression stage. The influencing factors of the prediction model include impactor mass, impactor velocity, contact surface size, and concrete strength and strain rate.

(3) The dynamic responses of CFST beams at the peak value stage were accurately predicted. This analysis calculation depended on the prediction model of the simplified trend curve and the travelling hinge theorem. The elastoplastic behaviour of CFST beams was also considered during the calculation.

Based on the proposed simplified trend curve and the travelling hinge theorem, a dynamic response analysis method for the peak value stage of CFST beams under lateral impact can be established. This method provided the predictions for the dynamic response of CFST beams reasonably. However, the transition stage in the simplified trend curve is marginally different from the FEA results, and the current work cannot simplify this stage more accurately. Therefore, more research is needed to further optimise the simplified trend curve.

\section{Acknowledgement}

The authors are grateful for the financial support of the National Key Research and Development Program of China (Grant No. 2016YFC0802205), the National Natural Science Foundation of China (Grant Nos. 51378427, 51678504), and the Department of Science and Technology of the Sichuan Province (Grant No. 2018JY0029).

\section{Notation}

\begin{tabular}{|c|c|c|c|}
\hline$a_{I L}$ & $\begin{array}{l}\text { Acceleration value of the impactor } \\
\text { at time } L\end{array}$ & $a_{I}$ & $\begin{array}{l}\text { Acceleration of the im- } \\
\text { pactor }\end{array}$ \\
\hline$V_{I L}$ & Velocity of the impactor at time $L$. & $V_{I}$ & Velocity of impactor \\
\hline$t_{L}$ & $\begin{array}{l}\text { Termination time of the local com- } \\
\text { pression stage }\end{array}$ & $W_{t}$ & $\begin{array}{l}\text { Displacement of im- } \\
\text { pactor }\end{array}$ \\
\hline$a_{b L}$ & $\begin{array}{l}\text { Acceleration value of the beam at } \\
\text { time } L\end{array}$ & $a_{b}$ & $\begin{array}{l}\text { Acceleration of the beam } \\
\text { impact point }\end{array}$ \\
\hline$V_{b L}$ & $\begin{array}{l}\text { Velocity of the beam impact point at } \\
\text { time } L\end{array}$ & $V_{b}$ & $\begin{array}{l}\text { Velocity of the beam im- } \\
\text { pact point }\end{array}$ \\
\hline$W_{b L}$ & $\begin{array}{l}\text { Deflection of the beam impact point } \\
\text { at time } L\end{array}$ & $W_{b}$ & $\begin{array}{l}\text { Displacement of the } \\
\text { beam impact point }\end{array}$ \\
\hline$\sigma_{3}$ & $\begin{array}{l}\text { Confining pressure around the con- } \\
\text { crete core }\end{array}$ & $v$ & Poisson's ratio \\
\hline$\varepsilon_{3}$ & $\begin{array}{l}\text { Average transverse strain of con- } \\
\text { crete }\end{array}$ & $A_{C}$ & Contact area \\
\hline$\varepsilon_{\mathrm{c} 3}$ & Compressive strain of concrete & $D$ & Diameter of the beam \\
\hline$f_{c}$ & Characteristic concrete strength & $T_{b}$ & $\begin{array}{l}\text { Thickness of the steel } \\
\text { tube }\end{array}$ \\
\hline$\varepsilon^{\prime}$ & local compression strain rate & $b$ & Width of the hammer \\
\hline$\alpha$ & Stress distribution coefficient & $E_{c}$ & $\begin{array}{l}\text { Elastic modulus of con- } \\
\text { crete }\end{array}$ \\
\hline$k$ & Empirical coefficient & $E_{s}$ & Elastic modulus of steel \\
\hline$M_{y}$ & $\begin{array}{l}\text { Dynamic yield bending moment of } \\
\text { the beam }\end{array}$ & $\rho_{c}$ & Density of concrete \\
\hline$M_{I}$ & $\begin{array}{l}\text { Bending moment value at impact } \\
\text { point } I\end{array}$ & $\rho_{s}$ & Density of steel \\
\hline$M_{N}$ & $\begin{array}{l}\text { Bending moment values of the } \\
\text { travelling hinge } N\end{array}$ & $L_{C}$ & Contact length \\
\hline$M_{F}$ & $\begin{array}{l}\text { Bending moment values of the } \\
\text { travelling hinge } F\end{array}$ & $\rho_{l}$ & $\begin{array}{l}\text { Beam quality per unit } \\
\text { length }\end{array}$ \\
\hline$M_{u}^{s}$ & $\begin{array}{l}\text { Static yield bending moment of the } \\
\text { CFST beam }\end{array}$ & $\xi_{N}$ & $\begin{array}{l}\text { Location of the } \\
\text { travelling hinge } N\end{array}$ \\
\hline$\theta_{N}$ & $\begin{array}{l}\text { Rotation angles of the travelling } \\
\text { hinge } N\end{array}$ & $\xi_{F}$ & $\begin{array}{l}\text { Location of the travel- } \\
\text { ling hinge } F\end{array}$ \\
\hline$\theta_{F}$ & $\begin{array}{l}\text { Rotation angles of the travelling } \\
\text { hinge } F\end{array}$ & $\xi_{N}^{\prime}$ & $\begin{array}{l}\text { Velocity of the travelling } \\
\text { hinge } N\end{array}$ \\
\hline$L_{N}$ & $\begin{array}{l}\text { Distances from impact point } I \text { to the } \\
\text { support } N\end{array}$ & $\xi_{F}^{\prime}$ & $\begin{array}{l}\text { Velocity of the travelling } \\
\text { hinge } F\end{array}$ \\
\hline$L_{F}$ & $\begin{array}{l}\text { Distances from impact point } I \text { to the } \\
\text { support } F\end{array}$ & $\xi_{0}$ & $\begin{array}{l}\text { Initial travelling hinge } \\
\text { position }\end{array}$ \\
\hline$K_{\phi}$ & Flexural rigidity of CFST members & $Q_{F}$ & $\begin{array}{l}\text { Shear force values of } \\
\text { hinge } F\end{array}$ \\
\hline$K_{\theta}$ & Static rotational stiffness & $Q_{N}$ & $\begin{array}{l}\text { Shear force values of } \\
\text { hinge } N\end{array}$ \\
\hline$K$ & Dynamic rotational stiffness & $C$ & Strain rate parameter \\
\hline$I_{S}$ & Inertia moment of steel tube section & $P$ & Strain rate parameter \\
\hline$I_{C}$ & $\begin{array}{l}\text { Inertia moment of core concrete } \\
\text { section }\end{array}$ & $l_{p}$ & $\begin{array}{l}\text { Equivalent length of the } \\
\text { hinge region }\end{array}$ \\
\hline$f_{c c}$ & $\begin{array}{l}\text { Concrete strength in consideration } \\
\text { of lateral confining pressure }\end{array}$ & $D I F$ & $\begin{array}{l}\text { Dynamic increase factor } \\
\text { of concrete }\end{array}$ \\
\hline
\end{tabular}

$D I F_{\theta} \quad$ Dynamic increase factor related to the rotational velocity of the hinge 


\section{References}

[1] Han L.H., Hou C.C., Zhao X.L. and Rasmussen K. J., "Behaviour of high-strength concrete filled steel tubes under transverse impact loading", Journal of Constructional Steel Research, 92, 25-39,2014.

[2] Mindess S. and Bentur A., "A preliminary study of the fracture of concrete beams under impact loading, using high speed photography", Cement and Concrete Research, 15(3), 474-484, 1985

[3] Yu Z.X., Zhao L., Liu Y.P., Zhao S. C., Xu H. and Chan, S. L., "Studies on flexible rockfall barriers for failure modes, mechanisms and design strategies: a case study of Western China", Landslides, 16(2), 347-362, 2019.

[4] Yu Z. X., Qiao Y. K., Zhao L., Xu H., Zhao S. C. and Liu Y. P., "A simple analytical method for evaluation of flexible rockfall barrier part 1: working mechanism and analytical solution", Advanced Steel Construction, 14(2), 115-141, 2018.

[5] Yu Z. X., Qiao Y. K., Zhao L., Xu H., Zhao S. C. and Liu Y. P., "A simple analytical method for evaluation of flexible rockfall barrier part 2: application and full-scale test", Advanced Steel Construction, 14(2), 142-165, 2018.

[6] Xu H., Gentilini C., Yu Z.X., Qi X. and Zhao S.C., "An energy allocation based design approach for flexible rockfall protection barrier", Engineering Structures, 173, 831-852, 2018.

[7] Liu C., Yu Z. X. and Zhao, S. C., "Quantifying the impact of a debris avalanche against a flexible barrier by coupled DEM-FEM analyses", Landslides, 2019.

[8] Yu Z. X., Zhao L., Guo L. P., Liu Y. P., Yang C. and Zhao, S. C., "Full-Scale Impact Test and Numerical Simulation of a New-Type Resilient Rock-Shed Flexible Buffer Structure", Shock and Vibration, 2019

[9] Yu Z. X., Yan S.W., Xu H. and Zhao S. C., "Mechanical behavior of piston rod pointsupported flexible buffer system", China Civil Engineering Journal, 11, 61-69, 2018. (in Chinese)

[10] Wang R., Han L.H. and Hou C.C., "Behavior of concrete filled steel tubular (CFST) members under lateral impact: Experiment and FEA model", Journal of Constructional Steel Research, 80(1), 188-201, 2013.

[11] Cotsovos D.M., "A simplified approach for assessing the load-carrying capacity of reinforced concrete beams under concentrated load applied at high rates", International Journal of Impact Engineering, 37(8), 907-917, 2010.

[12] Saatci S. and Vecchio F.J., "Effects of shear mechanisms on impact behavior of reinforced concrete beams", ACI Structural Journal, 106(1), 78-86, 2009.

[13] Pham T.M. and Hao H., "Prediction of the impact force on reinforced concrete beams from a drop weight", Advances in Structural Engineering, 19(11), 1710-1722, 2016.

[14] Lee E.H. and Symonds P.S., "Large plastic deformations of beam under transverse impact", Journal of Applied Mechanics-Transactions of the ASME, 19(3), 308-314, 1952.

[15] Parkes E.W., "The permanent deformation of a cantilever struck transversely at its tip", Proceedings of the Royal Society of London. Series A. Mathematical and Physical Sciences, 228(1175), 462-476,1955.

[16] Parkes E.W., "The permanent deformation of an encastre beam struck transversely at any point in its span", Proceedings of the Institution of Civil Engineers, 10(3), 277-304, 1958.

[17] Pham T.M. and Hao H., "Effect of the plastic hinge and boundary conditions on the impact behavior of reinforced concrete beams", International Journal of Impact Engineering, 102, 74-85, 2017.

[18] Pham T.M. and Hao H., "Plastic hinges and inertia forces in RC beams under impact loads", International Journal of Impact Engineering, 103, 1-11, 2017

[19] Liu S.W., Liu Y.P. and Chan S.L., "Advanced analysis of hybrid steel and concrete frames: Part 1: Cross-section analysis technique and second-order analysis", Journal of Constructional Steel Research, 70, 326-336, 2012.

[20] Liu S.W., Chan T.M., Chan S.L. and So D. K. L., "Direct analysis of high-strength concrete-filled-tubular columns with circular \& octagonal sections", Journal of Constructional Steel Research, 129, 301-314, 2017.
[21] Yang C., Yu Z. X. and Sun Y.P., “Axial residual capacity of circular concrete-filled steel tube stub columns considering local buckling", Advanced Steel Construction, 14(3), 496$513,2018$.

[22] Du Z.L., Liu Y.P., He J.W. and Chan S. L. "Direct analysis method for noncompact and slender concrete-filled steel tube members", Thin-Walled Structures, 135, 173-184, 2019.

[23] Aghdamy S., Thambiratnam D.P., Dhanasekar M. and Saiedi S., "Computer analysis of impact behavior of concrete filled steel tube columns", Advances in Engineering Software, 89, 52-63, 2015.

[24] Aghdamy S., Thambiratnam D.P., Dhanasekar M. and Saiedi S., "Effects of structurerelated parameters on the response of concrete-filled double-skin steel tube columns to lateral impact", Thin-Walled Structures, 108, 351-368, 2016.

[25] Yousuf M., Uy B., Tao Z. and Remennikov A., "Transverse impact resistance of hollow and concrete filled stainless steel columns", Journal of Constructional Steel Research, 82, 177-189, 2013.

[26] Yousuf M., Uy B., Tao Z., Remennikov A. and Liew J. R., "Impact behaviour of precompressed hollow and concrete filled mild and stainless steel columns", Journal of Constructional Steel Research, 96, 54-68, 2014.

[27] Qu H.Y., Li G., Chen S., Sun J. and Sozen M. A., "Analysis of circular concrete-filled steel tube specimen under lateral impact", Advances in Structural Engineering, 14(5), 941-952, 2011.

[28] Deng Y. and Tuan C.Y., "Design of concrete-filled circular steel tubes under lateral impact", ACI Structural Journal, 110(4), 691-701, 2013.

[29] Bambach M.R., "Design of hollow and concrete filled steel and stainless steel tubula columns for transverse impact loads", Thin-Walled Structures, 49(10), 1251-1260, 2011.

[30] Shakir A.S., Guan Z.W. and Jones S.W., "Lateral impact response of the concrete filled steel tube columns with and without CFRP strengthening", Engineering Structures, 116, 148-162, 2016.

[31] Wang Y., Qian X., Liew J.Y.R. and Zhang, M. H., "Impact of cement composite filled steel tubes: An experimental, numerical and theoretical treatise", Thin-Walled Structures, 87(1), 76-88, 2015.

[32] European Committee for Standardization (CEN)., Eurocode 1: Actions on structures, part 1-7: General actions -Accidental actions, London, UK, 2006

[33] Hallquist J.O., LS-DYNA keyword user manual-nonlinear dynamic analysis of structures, Livermore Software Technology Corporation, Livermore, CA, 2006.

[34] Malvar L.J., Crawford J.E., Wesevich J.W. and Simons D., "A plasticity concrete materia model for DYNA3D", International Journal of Impact Engineering, 19(9-10), 847-873, 1997.

[35] Cowper G.R. and Symonds P.S., Strain-hardening and strain-rate effects in the impact loading of cantilever beams, Brown Univ, Providence Ri, 1957.

[36] Comité Euro-International du Béton., CEB-FIP Model Code 1990, Redwood Books, Trowbridge, Wiltshire, UK, 1993

[37] Jones N., Structural impact, Cambridge University Press, 1997.

[38] Popov V.L., Contact Mechanics and Friction, Springer Berlin Heidelberg, Berlin,2010.

[39] Richart F.E., Brandtzaeg A. and Brown R.L., A study of the failure of concrete under combined compressive stresses, University of Illinois, Engineering Experimental Station, Bulletin, 1928.

[40] Ansari F. and Li Q., "High-strength concrete subjected to triaxial compression", ACI Materials Journal, 95(6), 747-755, 1998.

[41] Meyers M.A., Dynamic Behavior of Materials, John wiley \& sons, New York, 1994.

[42] Architectural Institute of Japan (AIJ)., Recommendations for design and construction of concrete filled steel tubular structures, Tokyo, Japan, 1997.

[43] Han L.H., "Flexural behaviour of concrete-filled steel tubes", Journal of Constructional Steel Research, 60(2), 313-337, 2004. 